\title{
ARBITRIUM EX MÁQUINA: UMA ABORDAGEM DE REGULAÇÃO RESPONSIVA À SOLUÇÃO DE CONTROVÉRSIAS EM PLATAFORMAS DIGITAIS.
}

\section{Resumo:}

\section{Raphael Ferreira Santana Silva ${ }^{1}$}

O objetivo do trabalho será investigar se a abordagem de regulação responsiva é capaz de contribuir para a superação do debate sobre a crise de legitimidade da atuação regulação da solução de conflitos através de plataformas. O artigo realiza na primeira parte um estudo descritivo sobre a solução de controvérsias por plataformas digitais, em especial do ODR. Na segunda parte, o foco é a relação entre o debate de legitimidade das plataformas e a regulação responsiva. Concluiu-se que a abordagem que pode ser um instrumental teórico que contribui para a legitimidade da solução de controvérsias realizada pelas plataformas digitais.

Palavras-chave: ODR, regulação responsiva,, plataformas digitais, dinâmica da regulação, legitimidade.

\section{ARBITRIUM EX MACHINE: A RESPONSIVE REGULATORY APPROACH FOR SOLVING DISPUTES IN DIGITAL PLATFORMS}

\begin{abstract}
:
The objective of the work will be to investigate if the responsive regulation approach is able to contribute to overcoming the debate about the legitimacy crisis when platforms acting solving conflicts. In the first part, the article conducts a descriptive study on the dispute settlement by digital platforms, especially the ODR. In the second part, the focus is on the relationship between the platform's legitimacy debate and responsive regulation. It was concluded that the approach that can be a theoretical tool that contributes to the legitimacy of the dispute solution carried out by digital platforms.
\end{abstract}

Keywords: ODR, responsive regulation, digital platforms, regulation dynamics, legitimacy.

\section{Introdução:}

Duas pesquisadoras necessitavam de um livro que não puderam encontrar nas livrarias do México, seu país de origem. Navegando na internet, as autoras conseguiram encontra-lo em uma livraria online brasileira. O livro foi comprado, pago de maneira online e recebido semanas depois. Contudo, justamente no capítulo do livro que precisavam para sua pesquisa,

\footnotetext{
${ }^{1}$ Mestrando em Direito da Regulação - FGV Direito Rio. Bolsista CAPES. Pesquisador no Grupo de Pesquisa em Moderação de conteúdo onilne do Centro de Tecnologia e Sociedade - CTS da FGV Direito Rio. Graduado em Direito pela Universidade Federal do Rio de Janeiro - UFRJ.
} 
algumas páginas estavam em branco. Elas contataram o vendedor no Brasil, que afirmou que nada poderia fazer. Diante desse impasse, as pesquisadoras não souberam como proceder. Deveriam acionar autoridades mexicanas? Brasileiras? Um tribunal internacional? Quais os princípios de direito internacional seriam aplicáveis? Qual seria a legislação aplicável? (ALBORNOZ; NÚRIA, 2012) Como se verá no decorrer desse trabalho, as transações em plataformas online demandaram o desenvolvimento de uma nova sistemática de solução de controvérsias, compatível com as transformações digitais.

$\mathrm{O}$ avanço da internet fez emergir mudanças comportamentais profundas, em especial nas relações comerciais e de consumo. O contínuo progresso e dinamismo da sociedade atual, principalmente em relação aos avanços tecnológicos, gerou um efeito disruptivo nas formas como estabelecemos as mais diversas relações em sociedade. Esse mandamento contínuo por modernização leva a destruição e diversificação das relações econômicas existentes. ${ }^{2}$ Nesse contexto, o uso de plataformas digitais se intensificou muito nos últimos anos, trazendo novos elementos de atenção às relações humanas, em especial às relações de consumo praticadas nas plataformas. Se, por um lado o uso das plataformas digitais permitiu que os consumidores realizassem uma busca global por bens e serviços de difícil acesso, por outro trouxe uma complexidade cada vez maior aos litígios que surgem dessas relações.

Contudo, essa mudança profunda no tecido social não foi isolada. Com o aumento da complexidade das dinâmicas sociais e o afloramento de riscos sistêmicos, foi preciso desenvolver uma nova função ao direito, que muitas vezes desafia princípios clássicos do sistema, tais como a legalidade estrita. Em um contexto de tamanha incerteza, a função regulatória traz consigo a busca por uma regularidade e um equilíbrio no funcionamento de algum subsistema, através de regras com alto de tecnicidade e complexidade, visando afetar o mínimo possível direitos e garantias fundamentais. Através da preponderância de escolhas técnicas, e não políticas, o agente regulador busca assegurar o equilíbrio sistêmico dos setores regulados. (GUERRA, 2016)

\footnotetext{
${ }^{2}$ Nesse contexto, no mesmo sentido: “...a sociedade moderna, em virtude de seu dinamismo, está acabando com suas formações de classe, camadas sociais, ocupação, papéis dos sexos, família nuclear, agricultura, setores empresariais e com os pré-requisitos e formas contínuas do progresso técnico-econômico, fazendo com que esse estágio de transformação e progresso se apresente como um tipo de modernização que destrói e que modifica as diversas formas sociais.” em GUERRA, Sérgio. Regulação Estatal e Novas Tecnologias, Interesse Público, v. 100, 2016.
} 
Assim sendo, um dos principais fatores de instabilidade na sociedade contemporânea é o avanço tecnológico. Ao mesmo tempo em que as novas tecnologias abrem um horizonte de possibilidades, também desafiam as organizações econômicas, sociais e até mesmo noções jurídicas consolidadas na doutrina. A criação de plataformas online como espaços em que se estabelecem relações sociais no meio digital, permitiu unir compradores e vendedores em todo o globo, permitindo a constituição de um verdadeiro mercado de consumo global e quase instantâneo. Por outro lado, a intensificação dessa dinâmica comercial desafiou diversas concepções jurídicas, como a legalidade estrita, o princípio da inafastabilidade de jurisdição e até a capacidade institucional do poder judiciário, como um todo.

O surgimento dos marketplaces globais e o intenso fluxo de relações de consumo por meio digital demandaram uma nova alternativa regulatória para a solução de conflitos no interior da plataforma. O paradigma da promoção estatal do direito do consumidor passou a ser substituído por uma ideia mais complexa, que demanda a participação de diversos atores, estatais e privados. O caráter global das transações, a alta especialidade das demandas no meio digital e a própria velocidade com que essas relações ocorrem abalaram a noção de jurisdição e regulação estatal das relações de consumo.

Nesse diapasão, as próprias plataformas digitais demandavam por maior estabilidade nas relações comerciais realizadas no interior do seu marketplace. Para que os compradores e consumidores se relacionassem por intermediação dessas empresas de tecnologia, era necessário que houvesse segurança entre as transações. As próprias empresas privadas se viram diante de uma necessidade de garantir um sistema de solução de controvérsias confiável que visasse um equilíbrio nas relações praticadas pelos meios digitais.

Por essa razão, as empresas de tecnologia criaram um novo sistema de solução de controvérsia: o Online Disputs Resolution - ODR. As plataformas não só passaram a desenvolver códigos de condutas para estabelecer direitos e deveres que regem as relações intermediadas, como também criaram um sistema próprio de solução de controvérsias. $\mathrm{O}$ ODR surgiu através uma demanda do próprio mercado das plataformas digitais. Plataformas que apresentaram um sistema de ODR confiável, seguro e que fizesse face aos desafios que emergiram com essa nova maneira de realizar relações de consumo, passaram a gozar de uma reputação melhor entre os usuários.

Assim sendo, diante do aumento da complexidade das relações digitais, novos atores e novas dinâmicas passaram a se inserir na regulação as relações sociais praticadas em 
plataformas digitais. O próprio mercado demandou um novo arranjo regulatório para soluções de controvérsias no meio digital. Era preciso superar o desafio de competência internacional de jurisdição, os custos de demandas judiciais e até da legislação aplicável a cada transação. Nesse contexto, o presente trabalho parte do pressuposto que as plataformas digitais regulam as relações sociais e econômicas praticadas por seu intermédio, através de códigos de conduta e de modelos próprios de solução de controvérsias.

Por essa razão, o objetivo desse artigo é investigar se as concepções de regulação responsiva e smart regulation são adequadas para descrever o fenômeno do ODR. A compreensão do ODR sob a racionalidade da regulação responsiva os smart regulation é importante para conhecer a dinâmica do próprio fenômeno, inclusive seus desafios teóricos, como uma possível crise de legitimidade. Para isso, o trabalho contará com duas partes. Primeiro o foco será descrever e compreender o contexto e as dimensões da solução de controvérsias por plataformas digitais, em especial do uso do ODR. Na segunda parte, o objetivo será desenvolver o conceito de regulação responsiva e smart regulation para compreender se são teorias adequadas a compreender o fenômeno da ODR.

\section{Uma visão geral sobre o uso do ODR para solução de controvérsias.}

O Online Dispute Resolution ODR é uma maneira encontrada pelas plataformas para responder aos conflitos gerados nas relações econômicas e comerciais, intermediadas por seu marketplace. Atualmente, só o eBay resolve cerca de 60 milhões de disputas anualmente. Caso o ODR do eBay fosse uma corte judicial, seria o maior tribunal de justiça do mundo. Além disso, aproximadamente $90 \%$ dessas disputas são resolvidas sem intervenção humana, como o uso do software Smartsettle que utiliza algoritmos de inteligência artificial para intermediar acordos entre as partes. (ARESTY, 2006)

É importante destacar que, através do e-commerce, os mercados se expandiram para incluir virtualmente qualquer pessoa com acesso à internet no planeta, modificando a forma como fazemos negócios hoje e aumentando nossa possibilidade de escolha a níveis impensáveis no passado (JEKER, 2006) Atualmente, as vendas em e-commerce já movimentam trilhões de dólares. (ARESTY, 2006)

Com isso, os conflitos não só se escalonaram vultuosamente, como também passaram a ter características mais complexas. Pessoas de culturas completamente diferentes, de países 
com sistemas jurídicos diversos passaram a transacionar através do espaço virtual. Nesse sentido, surge a necessidade de acomodar interesses e garantir a previsibilidade das disputas ocasionadas nessas relações.

Disputas podem ser compreendidas como um conflito em que uma das partes realiza um requerimento e a outra rejeita. (BRETT, 2007) No caso apresentado, as autoras desejavam o ressarcimento pelo livro e a livraria resistiu. Caberia às autoras, em um primeiro momento, exercer seu direito de ação e pleitear o vendedor em um tribunal. Contudo, as peculiaridades dos casos que envolvem transações online acabam por dificultar muito, e até inviabilizar, a solução judicial. Para que um juiz seja capaz de julgar adequadamente o caso, é preciso que seja possível conhecer os detalhes que envolvem os fatos, bem como a observância de formalidades que garantam justiça e equidade dos processos judiciais. (JEKER, 2006)

Assim, as partes devem ter possibilidade real de produzir de provas, para que o juiz da causa possa julgar a demanda de maneira adequada. $\mathrm{Na}$ maioria das transações de $e$ commerce, o contato entre o comprador e o vendedor é o mínimo possível para garantir a realização da transação. Muitas vezes, as próprias tradições jurídicas, históricas e culturais entre os atores da relação são completamente distintas, muitas vezes, habitando regiões geográficas completamente distintas. Toda essa diversidade dificultaria muito a um órgão judicial conhecer com a profundidade necessária uma demanda judicial sobre os fatos e às partes de exercerem seus direitos e garantias processuais fundamentais.

Ressalte-se ainda que, a própria velocidade e o imenso volume com que essas transações ocorrem exigem que as respostas às disputas seja veloz e especializada. É da natureza das transações de e-commerce a velocidade e, quase que, instantaneidade. Em poucos cliques, uma compra é realizada. Nesses casos, quando ocorre um litígio, a resposta deve ser minimamente compatível com a natureza dessas transações pra que seja eficiente.

Caso a resolução dos conflitos dependesse da observância das formalidades do processo judicial, em especial na produção de provas e no conflito internacional de jurisdição, o e-commerce incorporaria um risco de transação que inviabilizaria a natureza do negócio como é praticado hoje. As compras de natal deveriam ser realizadas com antecedência muito maior. Seria preciso maior cautela nas compras por impulso e que envolvessem transações com vendedores estrangeiros. O bem-estar advindo desse modelo de relações de consumo estaria comprometido. 
Por essa razão, o fim das fronteiras físicas e a velocidade das transações demandaram uma nova forma de resolução de controvérsias. Era preciso desenvolver um modelo menos formal, mas eficiente em garantir uma sensação de justiça e equidade entre os usuários, mas também que fosse orientado a observar o equilíbrio sistêmico do bem estar na plataforma. Nesse contexto surge o ODR, um modelo de solução de controvérsia utilizando o próprio meio digital. O uso do ODR pressupõe o consenso entre as partes que, como uma corte particular de solução de controvérsias da plataforma de e-commerce. Geralmente, as plataformas de ODR utilizam o parâmetro dos métodos alternativos de solução de controvérsias (ADR, em inglês). (JEKER, 2006)

O ODR parte de um pressuposto de "jurisdição consensual” e adota princípios básicos de mediação, negociação e arbitragem, mas através do uso intenso de tecnologia. Assim, o uso ODR se dá mediante um aceite contratual entre as partes que integram a plataforma. Portanto, é preciso uma manifestação de vontade para aderir ao sistema, mesmo que essa manifestação se dê em um verdadeiro contrato de adesão, no aceite dos termos e condições para o uso da plataforma e trate de questões existenciais, como as relações de consumo. Assim, embora possa-se conjecturar semelhanças inegáveis na adesão ao ODR com a cláusula arbitral, há algumas peculiaridades como a previsão em um termo de adesão e, principalmente, que o termo de uso não afasta a competência do juiz de direito de conhecer da causa. Contudo é preciso ressaltar que ainda que a inafastabilidade do poder judiciário não seja afetada, as decisões do ODR não são livres de consequências para as partes, o pode gerar questionamentos quanto a legitimidade dessa atuação.

Normalmente, as plataformas de ODR iniciam o procedimento através de uma negociação entre as partes envolvidas, mediada por uma inteligência artificial, um programa que realiza perguntas padrão, sugere e avalia as respostas. Em alguns casos, a plataforma usa uma técnica de blind-bidding, em que os usuários fazem propostas confidenciais de valores que aceitariam como negociação. Caso haja compatibilidade entre os valores, a plataforma considera o acordo fechado. Há o uso também de mediação online, nesse caso, através de um agente humano, mas sem o contato pessoal. É possível constatar algumas semelhanças com as técnicas clássicas de mediação, mas com um uso extensivo de tecnologias, como a inteligência artificial, os programas de aferição de propostas em segredo e o próprio uso das ferramentas online na mediação. (ALBONOZ, 2012) 
Caso não haja um acordo entre as partes ou até mesmo dependendo da baixa complexidade do litígio, é possível que seja instaurado um procedimento de "arbitragem online", com a assistência ou não de um agente humano. (ALBONOZ, 2012) Esses procedimentos são marcados pela informalidade e podem valer-se de diversos meios tecnológicos para a comunicação e produção de evidências, como troca de mensagens instantâneas, chats, videoconferências, e-mails. (JEKER, 2006) Esses procedimentos se diferenciam da arbitragem clássica não só pela forma de consentimento, mas também porque são permeados pelo uso de tecnologias. A comunicação entre as partes, produção de evidências são realizadas através de soluções tecnológicas, inclusive algumas decisões são tomadas por inteligência artificial.

Atualmente, a economia de plataforma já alcançou espaços maiores que o $e$ commerce. Através desse modelo de negócio, pessoas oferecem bens e serviços cada vez mais complexos. A prestação de serviço intermediada por aplicativos passou a ser a principal fonte de renda de boa parte da população mundial, em especial em um contexto de crise econômica e pandemia. Atividades típicas desse modelo de negócio como entregas e transportes passaram a ser consideradas serviços essenciais.

Além disso, outros aspectos da vida humana passaram a ser cada vez mais intermediados por plataformas. As redes sociais passaram a ser o lócus principal da produção dos discursos emanados pela sociedade, bem como do compartilhamento de momentos e lembranças do cotidiano. As empresas de busca na internet passaram a mediar quais informações devemos ter acesso ou não, de forma segmentada e particular para cada usuário. Inclusive relacionamentos amorosos tem suas plataformas próprias de conexão.

Por essa razão, é possível afirmar que as plataformas digitais constituíram um novo modelo de negócio, um novo mercado, com uma dinâmica diferente da economia não-digital, mesmo que as relações praticadas nesses espaços sejam necessidades e anseios anteriores até a própria internet. Toda essa mudança demanda arranjos regulatórios diferentes, que possuem uma outra lógica organizacional.

É possível dizer hoje que as plataformas se constituem como verdadeiros gatekeepers digitais. Assim como o proprietário pode permitir, restringir e, em certa medida, regular as atividades que são realizadas no interior de sua propriedade, as plataformas exercem o direito de banir usuários e estabelecem os códigos de conduta no uso desse espaço digital. (KADRI, 
2020) Nesse contexto, a internet passa a ter uma regulação, em alguma medida, similar a da propriedade privada do solo.

Contudo, isso gera diversas complexidades e questionamentos jurídicos. Como diversos aspectos da vida em sociedade foram digitalizados, as plataformas criaram um verdadeiro sistema judicial global. (LOO, 2020) Um common law da internet. (ARESTY, 2006) Regulando aspectos cada vez mais existenciais da vida e com um grau de complexidade crescente. A Amazon, por exemplo, tem um sistema de algoritmos que mapeia contas suspeitas de terem avaliações falsas, mas isso levou muitos vendedores a inserirem comentários falsos nas contas de outros vendedores com o objetivo de prejudica-los, ou fazer denúncias em massa. Isso pode levar a conta a ser bloqueada ou momentaneamente suspensa, afetando a competição em nível global. O AirBnb chega até a usar inteligências artificiais com análise preditiva para avaliar perfis que podem realizar atividades suspeitas antes que eles a realizem, interferindo nos direitos de propriedade e do exercício de atividade econômica. (LOO, 2020)

Nesse sentido, surge um debate sobre a legitimidade desse modelo de regulação pelas plataformas. As plataformas são atores do mercado, tem interesses econômicos próprios e não são imparciais. A legitimidade do estabelecimento dos códigos de conduta decorrem de uma concepção de direito de propriedade do domínio. Portanto, não partem de uma legitimidade política, eleitoral. Ao revés, partem da própria dinâmica do mercado e do modelo de negócio que atuam. Todavia, essa regulação passou a permear setores cada vez mais crescentes da vida em sociedade. Se, em décadas passadas, a principal questão levantada era a legitimidade de assegurar direitos de consumidor, agora outros questionamentos jurídicos surgem.

As redes sociais passaram a ser as principais reguladoras da liberdade de expressão no mundo. A imensa maioria dos debates sobre liberdade de expressão não são mais travados em cortes, mas por moderadores de conteúdo online. Os serviço de transporte e entrega, intermediados por plataformas digitais, passaram a ser a principal fonte de subsistência de grande parcela de pessoas ao redor do mundo. As informação que acessamos passaram a ser definidas pelo algoritmo do Google, de forma pessoal a cada usuário, sem que sequer se tenha conhecimento do seu código ou se o próprio conteúdo é verdadeiro ou não. Inclusive a forma como muitos estabelecem relacionamentos amorosos passou a ser mediada por plataformas, sob os termos de uso e a dinâmica própria. Todo esse contexto de digitalização das relações sociais foi aprofundado após o isolamento social e a pandemia do COVID-19. 
Portanto, emergem questões como a possibilidade das empresas interferirem nos direitos de competição em nível global, forçando suas preferências. $\mathrm{O}$ acesso massivo a dados de todas as transações e empresas que negociam na plataforma pode ser usado para favorecer alguns competidores no seu espaço. Surge a possibilidade de plataformas criarem assimetrias informacionais e seletividades para se autofavorecerem. ${ }^{3} \mathrm{~A}$ detenção dos dados dessas transações pode dificultar a pesquisa científica e inovação. As plataformas detém o poder de determinar quem possuirá acesso a informações sobre as relações realizadas e, assim, determinar quem poderá produzir pesquisa e inovação, atendendo aos interesses que lhe convierem.

Diante do exposto, é preciso superar o desafio da legitimidade da regulação perpetuada pelas plataformas. O presente trabalho não tem o propósito de superar todas as possíveis objeções, tampouco estabelecer um critério definitivo. O objetivo até aqui foi traçar um panorama da atuação da regulação realizada pelas plataformas, com especial ênfase a lógica do ODR. A próxima parte terá a finalidade de investigar os conceitos de regulação responsiva e smart regulation para poder determinar possíveis contribuições desses conceitos de regulação para o debate sobre a legitimidade dessa atuação das plataformas.

\section{Regulação responsiva e a resolução de controvérsias por plataformas.}

O conceito de regulação responsiva apresenta, de um modo geral, uma noção flexível de regulação. A regulação responsiva pressupõe que governos e autoridades devem ser responsivas, devem corresponder ao interesse público e da coletividade. Por isso, a regulação deve analisar ao ambiente regulatório e a conduta do agente, decidindo quando deve ser mais ou menos intervencionista. (BRAITHWAITE, 2010)

Parte-se da ideia que a regulação deve se basear em uma série de alternativas e possibilidades, o mais flexível possível, para que se aplique a casos individuais. (HARRIS, 2011) Abre-se uma margem de possibilidades para agente regulador de encontrar alternativas que garantam uma resposta mais adequada com o caso apresentado. $\mathrm{O}$ regulador passa a ter mais flexibilidade na eleição de alternativas.

\footnotetext{
${ }^{3}$ No caso South Airlines Co. X Farechase, Uma agência de viagens exigiu que a companhia aérea divulgasse em seu site, de forma pública os valores e horários de seus voos. in KADRI, Thomas, E. Digital Gatekeepers. Texas Law Rev. V.99, 2020
} 
Nesse ponto, a própria ideia de legalidade precisa ser revista. A lei passa a ter um caráter mais plástico, deixando espaços para que o agente regulador possa criar alternativas ou eleger os instrumentos previstos de forma mais livre, ampla e voltada a responder ao ambiente regulatório e à conduta dos agentes regulados. Por essa razão, é possível afirmar que uma regulação reflexiva ou responsiva leva à formas de legalidade responsivas e menos engessadas. (LEVI-FAUR, 2005)

Parte da doutrina entende que a regulação responsiva não deve incluir apenas atores governamentais. A sociedade civil, a autorregulação e outro atores sociais podem, também, ser incluídos como atores na regulatórias responsiva. (BRAITHWAITE, 2010) De fato, parece bastante coerente que um modelo de regulação orientado a apresentar resposta à condutas e ao ambiente regulatório integre os atores privados. A demanda por uma regulação reflexiva decorre justamente da complexidade das relações sociais e da necessidade de uma observação mais casuística e mais criativa. Excluir atores privados que constroem soluções no ambiente regulatório parece não ser compatível com essa ideia.

A regulação responsiva surge diante de um contexto de insatisfação das corporações diante da regulação. A regulação praticada era baseada em instrumentos de comado e controle e enforcement, que elevavam os custos de adequação às normas e apresentavam resultados práticos insatisfatórios. Era preciso compreender que as corporações são atores racionais que visavam maximizar seu benefício, mas também são dirigidos por cidadãos, que poderiam ser persuadidos a cumprir seus deveres cívicos.

Por essa razão, era necessário que o regulador tivesse mais flexibilidade para compreender os cenários e construir alternativas que fossem mais eficientes. Que apresentassem um custo menor de implementação, mas que fossem capazes de alcançar a finalidade que era esperada. Portanto, um ponto crucial da regulação responsiva é a dinâmica de alternância entre instrumentos de persuasão e comando e controle. Surge uma ideia de regulação piramidal, em que instrumentos de convencimento teriam preferencia sobre instrumentos punitivos e as punição deveria ser graduada e proporcional. Um princípio que o diálogo é a melhor regulação. (BRAITHWAITE, 2010) Assim, o custo do comando e controle deveria ser minoritário e restrito a hipóteses em que a persuasão falhasse. A progressão de punições oferece ao agente racional uma ponderação para que adeque seu comportamento antes que houvesse uma punição. 
Desse modo, a pirâmide da regulação responsiva teria como base uma ideia de justiça restaurativa (restorative justice), baseada na virtuosidade da adesão do agente regulador. Depois a aplicação de medidas de dissuasão (deterrence), visando convencer por meio da ameaça o agente racional. Por fim, caso não seja possível responder ao problema regulatório de nenhuma das outras formas, é necessário adotar sanções ao agente regulado. Nessa hipótese, quando a regulação menos intervencionista e menos gravosa, deve-se aplicar a regulação mais sancionadora ao agente que seja incompetente ou irracional em aderir voluntariamente ao objetivo regulatório. (BRAITHWAITE, 2010)

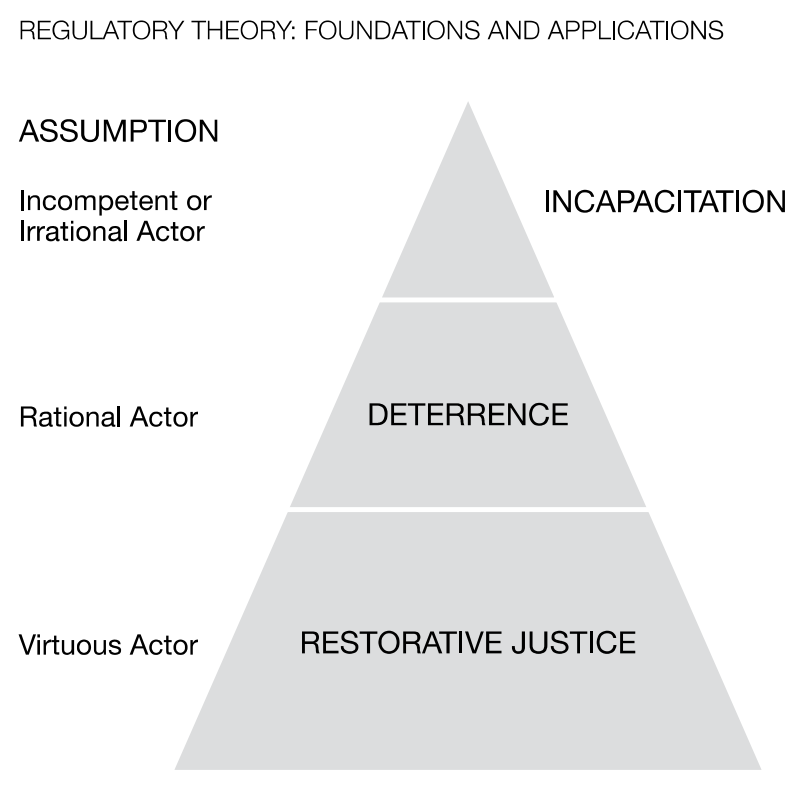

Uma das bases para o desenvolvimento de uma regulação mais responsiva é a boa relação entre reguladores e regulados. É preciso que o ambiente seja menos adversarial e mais colaborativo, cooperativo. Nesse contexto, o uso excessivo de medidas punitivas dificultaria a colaboração entre os agentes de mercado e o regulador, diminuindo sua adesão voluntária ao propósito. Esse modelo de regulação se baseia na ideia de compliance e autodeclaração, por isso deve ser sensível a interações sociais e os trade offs envolvidos. (BALDWIN; BLACK, 2008)

A regulação responsiva também tem muitos reflexos na resolução de conflitos. É preciso que se incentive métodos de superação de controvérsias fora das cortes e menos adversariais. A própria ideia de legalidade adversarial é mitigada por uma visão mais responsiva. A lei deve ser um instrumento para a superação do conflito, de maneira menos 
invasiva possível. Trata-se de uma visão que compreende que a superação de conflitos tem múltiplas formas e não poderia ser reduzida à litigância judicial. É preciso promover os métodos alternativos de solução de controvérsias e considerar a multiplicidade de atores sociais que podem atuar nesse processo. (LEVI-FAUR, 2005)

Ademais, a regulação responsiva pressupõe uma análise sistêmica dos conflitos. Investiga-se todo o impacto da resolução do conflito em todo o cenário regulatório e não apenas a aplicação da lei a um caso específico. Isso permite que o método de resolução privilegie alternativas menos drásticas, que promovam o diálogo e a colaboração em cada caso, mas que sejam suficientes para garantir uma previsibilidade e segurança nas relações sociais como um todo. Com isso, seria possível poupar recursos financeiros e garantir uma celeridade maior, produzindo soluções mais eficientes para garantir a pacificação social.

Por essa razão, a solução de controvérsias através de instrumentos tecnológicos, com o protagonismo das plataformas digitais pode se constituir como uma alternativa responsiva aos litígios. Em primeiro lugar, porque mesmo as partes acordando pela adoção da decisão da plataforma, não há impeditivos para que as partes busquem o judiciário. A inafastabilidade do poder judiciário é mantida, mesmo que, na prática, essa forma de solução de controvérsia seja inviabilizada pelos conflitos internacionais de competência, pelo alto custo da litigância e pela falta de especialização das cortes de justiça. Com isso, é possível concluir que a resolução de controvérsias através das plataformas é apenas uma maneira de superação de conflito, que não exclui outras formas, a depender do caso concreto.

Contudo, é preciso observar que a própria solução apresentada pela plataforma deve obedecer os postulados da regulação responsiva. É fundamental que a atuação das plataformas diante das controvérsias privilegie métodos menos invasivos e que garantam a conciliação e composição de interesses, inclusive como forma de superar os questionamentos de legitimidade. A atuação das plataformas poderá ser considerada mais legitima se for menos invasiva e partir de formas de composição de interesses e conciliação. É importante que a atuação das plataformas seja pautada no diálogo entre as partes, em soluções mais conciliadoras.

Portanto, as plataformas digitais podem ser consideradas agentes reguladoras pois estabelecem normativas e buscam solucionar conflitos pelos métodos digitais. Por essa razão, considera-se essas empresas como agentes reguladores das relações realizadas através das plataformas. Todavia, para que sua atuação tenha menos questionamentos de legitimidade é 
preciso que sua atuação seja mais casuística, mais plástica e garanta aos agentes regulados espaços de composição das decisões. É necessário observar os conflitos de forma individual, garantindo o ideal de justiça aos casos concretos, mas sem deixar de observar os efeitos sistêmicos, priorizando a construção de um ambiente saudável na plataforma.

\section{Conclusão:}

O avanço tecnológico é uma das marcas fundamentais da pós-modernidade. A tecnologia é capaz de criar novas soluções, construir novos horizontes de possibilidades. Todavia, ao mesmo tempo que tem potencial de trazer bem-estar e desenvolvimento sócio econômico, as inovações também desafiam noções jurídicas consolidadas, trazendo novos desafios e tornando institutos jurídicos seculares obsoletos.

Nesse contexto, surgiu a ideia do direito da regulação e, em especial, da regulação responsiva. O direito passando a ser orientado a apresentar respostas flexíveis a esses desafios complexos. Em um mundo marcado pela instabilidade, soluções engessadas e rígidas acabam por tornar-se inadequadas em pouco tempo, pois os desafios que buscavam solucionar já não são os mesmos. O grade desafio é conseguir um mínimo de previsibilidade e estabilidade em um momento histórico marcado por riscos sistêmicos e múltiplas incertezas.

Assim sendo, as plataformas digitais passaram a apresentar soluções inovadoras para problemas já existentes na sociedade. As empresas de tecnologia permitiram a constituição de um mercado de consumo global, permitindo unir compradores e vendedores em regiões geográficas díspares e de tradições sócio culturais igualmente diversas. A economia de plataformas avançou e passou a permear outros aspectos da existência humana. Se antes as plataformas eram restritas às relações de consumo, hoje múltiplos aspectos da experiência humana passaram a ser mediados por essas ferramentas. De amizades, romances à manifestações políticas e ativismo político. Nunca fomos tão conectados, tão unidos em toda nossa história.

Contudo, toda relação humana é marcada por conflitos e dissidências e coube às próprias plataformas encontrarem alternativas para a solução de controvérsias. Houve uma demanda do próprio mercado para garantir um mínimo de estabilidade e segurança nos espaços digitais mediados por essas empresas. Os métodos de solução de conflitos se tornaram cada vez mais complexos e sofisticados, utilizando como inspiração métodos 
alternativos de solução de controvérsias já consolidados pelo direito, mas adaptados às demandas digitais.

Com isso, novos questionamentos jurídicos surgiram, em especial sobre a legitimidade dessas plataformas em decidir aspectos cada vez mais sensíveis. Antes, as decisões de plataformas eram restritas às relações de consumo, o que, por si só, já abalava muitos paradigmas tradicionais do direito. Atualmente, avança-se para aspectos cada vez mais existenciais, como a liberdade de expressão no meio digital, a liberdade de informação e até nas relações íntimas de afeto. Por essa razão, é fundamental investigar e construir alternativas ao desafio da legitimidade desse modo de regulação.

O fundamento desse modelo de regulação está no direito de propriedade, onde as plataformas poderiam ser o gatekeeper das relações digitais em virtude de possuírem o domínio. Entretanto, é preciso avançar em termos argumentativos. Por isso, é fundamental reconhecer a regulação perpetrada pelas plataformas digitais se insere em um contexto de regulação responsiva. As plataformas conseguem apresentar respostas mais adequadas aos conflitos surgidos no ambiente regulatório que atuam, por serem mais céleres, eficientes e especializadas que os meios estatais. É preciso também que a atuação dessas empresas seja igualmente orientada pelos princípios da regulação responsiva, em especial destinando esforços para que a solução dos conflitos privilegie soluções que conciliem os interesses em disputa e sejam menos invasivas possível.

A economia digital possui características peculiares e próprias. A possibilidade de criação de um mercado global através do e-commerce colocou as relações comerciais em uma escala nunca antes vistas. A possibilidade de trocar informações, se comunicar trouxe ferramentas poderosas para difundir mensagens e produzir conteúdo. Essas novas possibilidades seriam apenas caprichos em livros de ficção científica no passado, mas hoje são naturais e estão a nossa disposição no dia-a-dia.

Portanto, é cediço que a economia de plataforma é capaz de trazer muitos benefícios e bem-estar para a humanidade, mas também traz novos desafios. A superação de antigos obstáculos, como a dificuldade de encontrar um livro raro trouxe novos questionamentos. A economia digital traz consigo outras contendas, como a necessidade proteção de dados e privacidade, o controle do discurso de ódio dentre outras questões que não permeavam o debate desses setores na vida em sociedade. Por essa razão, é fundamental que a regulação produza respostas flexíveis e sensíveis às mudanças sociais e aos direitos em jogo. 


\section{BIBLIOGRAFIA:}

ALBORNOZ, María M. Martín, Núrua G. Feasibility Analysis of Online Dispute Resolution in Developing Countries, em The University of Miami Inter-american Law Review, Miami, v. 44. 2012.

ARESTY, Jeff et al Expand Your Practice with Online Dispute Resolution Technology, GPSolo, v. 32, n. 1, 2015.

BALDWIN, Robert; BLACK, Julia. Really Responsive Regulation. The modern law review, v71, n. 1, 2008

BRAITHWAITE, John. Types of responsiveness, Regulatory theory: Foundations and applications. Peter Drahos, 2010

BRETT, Jeanne M. et al Sticks and Stones: Language, Face, and Online Dispute Resolution, The Academy of Management Journal, v. 50 n. 1, 2007

GUERRA, Sérgio. Regulação Estatal e Novas Tecnologias, Interesse Público, v. 100, 2016.

HARRIS, Nathan. Does Responsive Regulation Offer an Alternative? Questioning the Role of Formalistic Assessment in Child Protection Investigations, The British Journal of Social Work, v. 41, n.7, 2011

JEKER, Virginia La Torre. et al E-Transaction Law and Online Dispute Resolution: A Necessity in the Middle East, Arab Law Quarterly, v. 20, n.1 2006

KADRI, Thomas, E. Digital Gatekeepers. Texas Law Rev. V.99, 2020 
LEVI-FAUR, David. The Political Economy of Legal Globalization: Juridification, Adversarial Legalism, and Responsive Regulation. A Comment. International Organization, 2005, v 59, n.2

LOO, Rory, V. Federal Rules of Platform Procedure. University of chicaco Law Rev., 2020 